\title{
Visualized Analysis of the Communication Effects of the Sina Weibo/Micro-blog of Chinese National Geography
}

\author{
By Yue Chai \\ Qiaolei Jiang \\ Wenying $\mathrm{Wu}^{+}$
}

\begin{abstract}
In China, the emergence of various social media have dramatically changed the situation of media ecology and rapidly infiltrated into all kinds of traditional media. Many traditional scientific magazines or journals also regard micro-blog as a new platform to diffuse scientific information. Taking the Sina Weibo/micro-blog account of Chinese National Geography $(C N G)$ as a case study, this research aimed to figure out the development path of popular science magazines within the era of media convergence. Content analysis was conducted based on the 6,882 posts/articles and related data collected from 22 September 2009 to 21 September 2013. Visualized software PKUVIS was used to show the transmission path, levels and effects, based on those hot CNG micro-blog posts being highly forwarded or commented. The findings showed that the patterns of CNG micro-blog posts were related to content rather than time. The CNG micro-blog posts showed declined rate of originality, stable ratio of images, and increased proportion of links. Although limited within 140 words, the content of CNG microblog posts still maintained its diversity and professionalism. According to the visualized analyses, when the micro-blog posts focused on scientific information, long communication chains appeared and wide communication range was formed as it being forwarded by some famous or popular verified followers $(V$-fans). These findings may provide insights for future development of science magazines' micro-blog.
\end{abstract}

Keywords: Chinese National Geography, communication effect, micro-blog (Weibo), visualized analysis

\section{Introduction}

Facing the mobile Internet, science communication have been changing in audience participation, communication channels and consumption patterns of information. In this situation, the traditional popular science journals have to adapt to the network media with chaning the communication mode from the mechanical top-down to the active participation. Some popular science periodicals quickly catch the big opportunity, they take the new media as tools to form more powerful communication effect, one of the most successful cases is Chinese National Geography (CNG).

As the CNG's predecessor, Geography was founded in 1950 to spread basic scientific knowledge and scientific spirit and it later replaced by CNG which spreads geography stories and reports scientific developments since 1998 (Zhao,

\footnotetext{
* Lecturer, Dalian University of Technology, China.

${ }^{\dagger}$ Associate Professor, Dalian University of Technology, China.

${ }^{+}$Associate Professor, Dalian University of Technology, China.
} 
2014). In 2004, CNG published BOWU including biological, plants, minerals and physiology as the youth edition, and in 2008, CNG published Chinese Heritage and set up a CNG website to take the first step into digital new media platform to expand the digital transmission and publish developments in new media.

The first Sina Micro-blog article of CNG was posted on September 22, 2009, and it had more than 3.64 million fans by the end of 2014. While the first article Sina Micro-blog of the Leading Discovery Magazine of China was posted on September 10, 2009 and it had more than 50 thousand fans, the first Sina Micro-blog article of Science Pictorial was posted on March 7, 2010 and it had only 20 thousand fans. Although the number of fans is just one of the indicators of development of Sina Micro-blog, but there is no doubt that it can reflect the periodical brand influence, effective transmission, journal distribution and development trend of its digital publishing market, so the Sina Micro-blog of CNG can be viewed as the most mature representative of the current popular science periodicals.

The Logo of Micro-blog of CNG is its Titles Logo in red and white which is same with the Logo of the magazine, highly consistent with its brand image. Besides it includes authentication information and other basic module, there are two prominent features: the first is the integration of CNG digital brand, on the right side of the home page, there are CNG WeChat account, QR code for people to click or scan, basic information section providing links of CNG website, Micro-blog of BOWU, the Chinese Heritage, China National Geographic Books, Campus Xing Zhi Ke and CNG WeChat account, and in the people recommended section there are the CNG president Shuanke Li, managing editor Zhiqiang Shan and assistant president Huaye Cai; the second is the recommendation for the main content, that the important Micro-blog will be published on the home page, the topic events will be laid out on the headlines position which can be slide to change.

CNG account follows a total of more than 140 other weibo accounts, which can be divided into the following five categories: public institutions, such as the United Nations, UNESCO, the Sound of the Chinese Academy of Sciences, Geographical Society of China, etc; other mass media such as People's Daily, Xinhua Viewpoint, Sina Sports, Titanium Media; relevant cooperation agency or advertiser, such as the Toyota Camry, Johnson Lenses, Raredoc new Asian directors Plan; brand associated organizations or individuals, such as Geography Quest, CNG Donkey the World, Shuanke Li etc; and tourism geography company or travel bloggers. These institutions or individuals not only provide information clues and references for $\mathrm{CNG}$, but also support the events carried out by it. There are two distinct characteristics can be figured out from the accounts following it: first, there are a lot of attention paid by photographers, such as Man Chen, Rong Yuan, Jing Yan, Xiaojie Shui etc. to establish a solid and scale channels of photography; Second, due to the Amazing XinJiang theme, there are nearly 20 public-account followers related of Xinjiang taking about $13 \%$ of the total accounts numbers, it shows the importance attached to the special topic, also reflects the attention paid to collection and use of network resources in the era of digital publishing. 


\section{Literature Review}

In China, there have been more than 30 thousand papers of micro-blog since 2010. These papers mainly studied the characteristics, function, public opinion and the role of commercial, etc. But only about 50 papers studied the micro-blog of periodicals, especially the marketing of the academic periodicals. Papers about micro-blog of popular science periodicals is very litter although it is very important in these days.

There have been some empirical studies of magazines' micro-blog, such as Chang, Li, and Chen (2012) collected three popular science periodicals' microblogs within a week to analysis the content; Guangbin Zhang (2012) studied the top10 accounts of popular science micro-blogs for 14 months, sum up the experiences of micro-blogs' publishing with an example of "Nature \& SciTech"; Qiu, Huang, and Lin (2013) analyzed 9 health and popular science magazines' micro-blogs contents within a week. These studies describes the characteristics of micro-blogs of the magazines, especially the science magazines. However, as science magazines' micro-blogs' unbalanced developments, the analysis based on multi-levels of samples are difficult to provide effective advice to these science magazines. Also, data of a week or so are not typical and representative due to the small amount and the influence of some special day.

\section{Methods}

Each micro-blog is limited within 140 words which can include text, images, links, audio, video, gif maps etc. People can comment, forward and thumb up the micro-blog, they also can @ other account to inform them or interact with them. When somebody wants to start a micro-blog interesting discussion topic, he/she can use \# as a label to focus on the relevant content, which make it easier for people to read and comment on. These indicators can be used to analyze the statistical trend of the content, value and dissemination of micro-blog posts.

In this paper, content analysis was conducted based on the 6,882 posts/articles and related data collected from 22 September 2009 to 21 September 2013. Visualized software PKUVIS was used to show the transmission path, levels and effects, based on those hot CNG micro-blog posts being highly forwarded or commented.

\section{Analysis}

\section{Patterns of Micro-Blog Posts}

The findings showed that the patterns of CNG micro-blog posts were related to content rather than time. As shown in Figure 1, the monthly average number of CNG micro-blog shows a gradual upward trend with time. CNG released 52 posts on average per month which involved upcoming events, live 
webcast and micro-blog topics etc. However, we found most posts in poor wording, even just a short excerpt from an online article, lack of integrity in writing forms and failed to make full use of the micro-space. Subsequently, the number of CNG micro-blog which increasing yearly with broader areas of contents involved, reached 212 on average each month, that is 7 posts each day, and by 2012 the micro-blog publish formed its scale and remained a relatively stable situation.

Figure 1. The Number of CNG Micro-Blog Posts

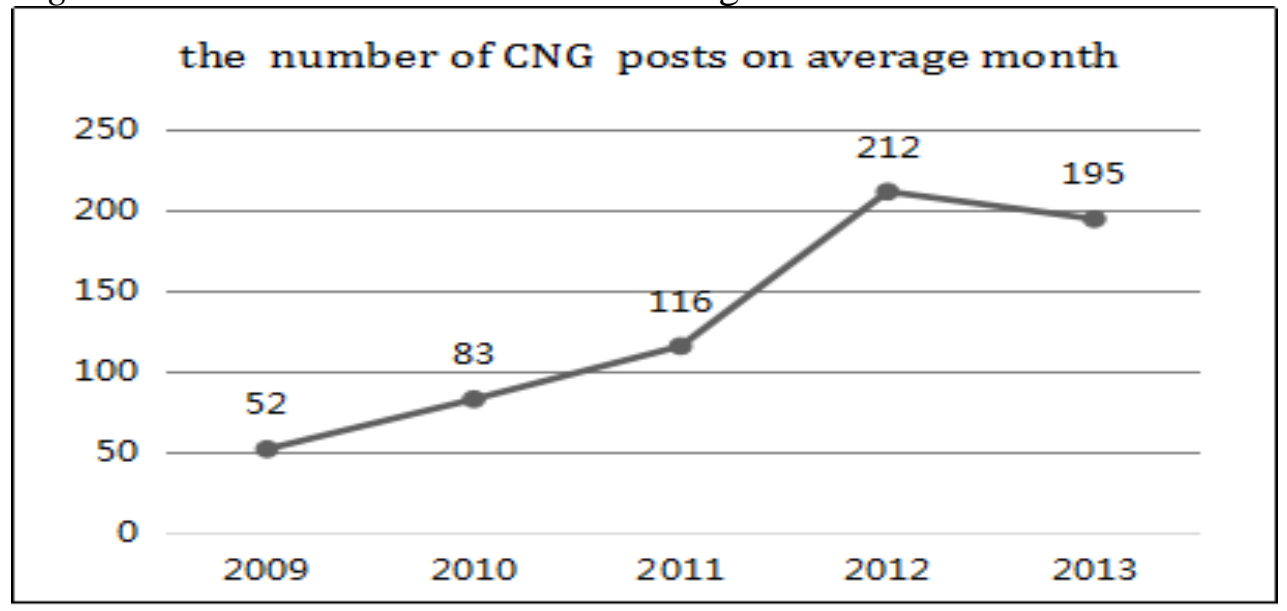

Considering the time dimension separately, the monthly number of CNG micro-blog posts shows an imbalanced state. Data from 2010 to 2012 in Table 1 indicates a large gap between the lowest and highest annual information number, the widest ratio reached 8:1. The topics in high information value months of 2010 covered activities to celebrate the $60^{\text {th }}$ anniversary, Campus Zhike, ZhouQu mudslide, Iodized salt event and so on. In 2011, extensive micro-blog topics were planned in May, June and a large amount of lottery information and forwarding interaction were collected in December. There were considerable micro-blog topics and live activities.

Table 2. The Distribution of CNG Micro-blogs' Posts

\begin{tabular}{|l|c|c|c|c|c|c|}
\hline Year & \multicolumn{3}{|c|}{ Three Months of Minimum } & \multicolumn{3}{c|}{$\begin{array}{c}\text { Three Months of Maximum } \\
\text { Number }\end{array}$} \\
\hline 2010 & May & February & March & July & August & September \\
\hline Posts & 23 & 27 & 42 & 179 & 134 & 107 \\
\hline 2011 & February & October & November & June & December & May \\
\hline Posts & 23 & 78 & 81 & 188 & 179 & 177 \\
\hline 2012 & April & June & July & October & November & December \\
\hline Posts & 99 & 106 & 107 & 467 & 465 & 354 \\
\hline
\end{tabular}

\section{The Value of Micro-blog}

The originality of micro-blog in two dimensions can reflect the periodical of core level and open, both to reflect the scientific and professionalism of the 
contents, and to embody the interactive and confirmation of resemble microblog from another perspective. Micro-blog images can not only weaken the "professional barriers" of popular science periodicals but also enhance the "first eye effect" and the attraction to the audience, and also help them understand of the scientific content. Micro-blog links strengthen the added value and integrity of information; prevent popular science periodical micro-blogs from the deconstruction of fragmented dissemination mode by 140 words.

Table 2. The Value Analysis of CNG Micro-Blog

\begin{tabular}{|c|c|c|c|}
\hline Year & Originality & Images & Links \\
\hline 2009 & $78.26 \%$ & $40.10 \%$ & $52.66 \%$ \\
\hline 2010 & $62.87 \%$ & $48.54 \%$ & $65.49 \%$ \\
\hline 2011 & $43.50 \%$ & $39.55 \%$ & $74.23 \%$ \\
\hline 2012 & $50.63 \%$ & $49.61 \%$ & $83.86 \%$ \\
\hline 2013 & $42.72 \%$ & $43.06 \%$ & $75.44 \%$ \\
\hline
\end{tabular}

The analysis value of the above-mentioned three factors were shown in Table 2 , the original rate of $\mathrm{CNG}$ shows a declining trend, which amounted to $78.26 \%$ in 2009 , followed by a decrease to about $50 \%$; usage of pictures is relatively stable in about $45 \%$, including the original images of journal articles and special covers that improve audience participation, such as the "daily chart" column which received attention, within a regular release, and link utilization rate increases year by year and has reached $80 \%$ or so in recent two years.

Table 3. The Statistical Analysis of Forwarding Posts

\begin{tabular}{|c|c|c|c|c|c|}
\hline Year & $\begin{array}{c}\text { Forwarding } \\
\text { Number }\end{array}$ & $\begin{array}{c}\text { Self-Forwarding } \\
\text { Posts }\end{array}$ & $\begin{array}{c}\text { Self } \\
\text { Rate }\end{array}$ & $\begin{array}{c}\text { Forwarding } \\
\text { Others }\end{array}$ & $\begin{array}{c}\text { Forwarding } \\
\text { Rate }\end{array}$ \\
\hline 2009 & 45 & 1 & $2.22 \%$ & 44 & $97.78 \%$ \\
\hline 2010 & 368 & 47 & $12.77 \%$ & 321 & $87.23 \%$ \\
\hline 2011 & 787 & 48 & $6.10 \%$ & 739 & $93.90 \%$ \\
\hline 2012 & 1254 & 163 & $13.00 \%$ & 1091 & $87.00 \%$ \\
\hline 2013 & 1003 & 48 & $4.79 \%$ & 955 & $95.21 \%$ \\
\hline
\end{tabular}

Unlike previous third-party intervention transmission mode such as media interviews, the autonomy of micro-blog provides convenience for direct information dissemination between the journal and the public. This kind of independent, direct and interactive communication mode, to some extent, effectively avoid the possible decoding errors in the information transferring process. Even if it may cause public information misreading, the press has the opportunity to eliminate it through the network (Zhang, 2012). Thus interaction is an important manifestation of vitality and the value of popular science periodical micro-blog. In order to better understand its original value and brand awareness, we analyzed the posts forwarded by them. As shown in Table 3, self-forwarded posts of CNG micro-blog take a small proportion of less than $10 \%$ the predominant forwarding posts indicate its active interaction.

Further analyses of interactive accounts are shown in Table 4. Though forwarding micro-blogs take a large proportion, the top five forwarding 
accounts are closely inter-related with the brand association and account for more than $50 \%$. According to the data, the continued decline of CNG microblog's originality did not affect its core value and professionalism, and its position was not destroyed by the fragmentation of the content from its release to spread (Chang et al., 2012). The unity of internal brand and the core value both activated the micro-blog and promoted the overall brand of the journal, formed a win-win situation.

Table 4. The Analysis of Accounts Forwarded by CNG

\begin{tabular}{|c|c|c|c|c|c|c|c|}
\hline \multirow{2}{*}{$\begin{array}{l}\text { Year } \\
2009\end{array}$} & \multirow{2}{*}{$\begin{array}{c}\begin{array}{c}\text { Forwarded } \\
\text { Number }\end{array} \\
44 \\
\end{array}$} & \multicolumn{5}{|c|}{ Top 5 Accounts Forwarded by CNG } & \multirow{2}{*}{$\begin{array}{r}\text { Proportion } \\
81.82 \%\end{array}$} \\
\hline & & $\begin{array}{c}\text { Bowu } \\
\text { magazine } \\
(11)\end{array}$ & $\begin{array}{c}\text { travelers } \\
(8)\end{array}$ & $\begin{array}{c}\text { Lei } \\
\text { Yongqing } \\
(8)\end{array}$ & $\begin{array}{c}\mathrm{Li} \\
\text { Shuanke } \\
(5)\end{array}$ & $\begin{array}{c}\text { Geographic } \\
\text { bear, } \\
\text { Chinese } \\
\text { heritage } \\
\text { (4) }\end{array}$ & \\
\hline 2010 & 321 & $\begin{array}{c}\text { Chinese } \\
\text { heritage } \\
\quad(76)\end{array}$ & $\begin{array}{c}\text { Bowu } \\
\text { magazine } \\
(36)\end{array}$ & $\begin{array}{c}\mathrm{Li} \\
\text { Shuanke } \\
(27)\end{array}$ & $\begin{array}{c}\text { Cai } \\
\text { Huahua } \\
(23)\end{array}$ & $\begin{array}{c}\text { CNG } \\
\text { mobile } \\
\text { newspaper } \\
(15)\end{array}$ & $55.14 \%$ \\
\hline 2011 & 739 & $\begin{array}{c}\text { CNG } \\
\text { network } \\
(155)\end{array}$ & $\begin{array}{c}\mathrm{CNG} \\
\text { books } \\
(84)\end{array}$ & $\begin{array}{l}\text { Dan } \\
\text { Zhiqiang } \\
(70)\end{array}$ & $\begin{array}{c}\mathrm{CNG} \\
\text { mobile } \\
\text { newspaper } \\
(52)\end{array}$ & $\begin{array}{c}\text { Bowu } \\
\text { magazine } \\
(37)\end{array}$ & $53.86 \%$ \\
\hline 2012 & 1,091 & $\begin{array}{l}\text { CNG } \\
\text { Books } \\
(204)\end{array}$ & $\begin{array}{c}\text { Bowu } \\
\text { magazine } \\
(166)\end{array}$ & $\begin{array}{l}\text { Jeep } \\
\text { China } \\
(115)\end{array}$ & $\begin{array}{c}\text { Chinese } \\
\text { heritage } \\
(84)\end{array}$ & $\begin{array}{c}\text { Geography } \\
\text { quest, Dan } \\
\text { Zhiqiang } \\
(60)\end{array}$ & $57.65 \%$ \\
\hline 2013 & 955 & $\begin{array}{l}\text { CNG } \\
\text { Books } \\
(180)\end{array}$ & $\begin{array}{c}\text { Bowu } \\
\text { magazine } \\
\text { (167) }\end{array}$ & $\begin{array}{c}\text { Chinese } \\
\text { heritage } \\
(105)\end{array}$ & $\begin{array}{c}\text { Campus } \\
\text { Zhike } \\
(82)\end{array}$ & $\begin{array}{c}\text { Geography } \\
\text { quest } \\
(63)\end{array}$ & $62.51 \%$ \\
\hline
\end{tabular}

\section{Contents of Micro-blog}

With the word limit of 140 words, the popularization effect of science also faces the challenge. Some suggested that cutting down the number of the words may lead to decrease of professionalism, and being taken "out of context" will inevitably cause the collapse of scientific value. From this perspective, links were used to contribute to indispensable complement and extensive reading, and also break the limitation of "fragmentation", provide the depth of content and professional value of micro-blog to some extent ( $\mathrm{Li}, 2014)$.

Statistical analysis of CNG micro-blog links were conducted, one type linked to the official website of CNG. Table 5 shows the analysis of the main contents, the contents of the CNG network presents decreasing trend over time. The main content transformed particularly from the initial commercial promotion, scientific popularization to service class, activity class and special topic information, with the scientific popularization reducing and service enhancing. In the digital platform of micro-blog, the intervention of the CNG official website is getting less and less, and gradually turns to providing information service platform for the audience. 
Table 5. The Content of CNG Official Links

\begin{tabular}{|c|c|c|c|c|c|}
\hline Year & $\begin{array}{c}\text { Number } \\
\text { of links }\end{array}$ & \multicolumn{3}{|c|}{ Top 3 Columns } & Proportion \\
\hline 2009 & 95 & $\begin{array}{c}\text { Geography } \\
\text { Forum (41) }\end{array}$ & $\begin{array}{c}\text { Geography } \\
\text { mall (9) }\end{array}$ & $\begin{array}{c}\text { Geography } \\
\text { Information (6) }\end{array}$ & $58.95 \%$ \\
\hline 2010 & 258 & $\begin{array}{c}\text { Geography } \\
\text { Forum (65) }\end{array}$ & $\begin{array}{c}\text { Geography } \\
\text { E (37) }\end{array}$ & $\begin{array}{c}\text { Geography } \\
\text { information (27) }\end{array}$ & $50 \%$ \\
\hline 2011 & 243 & $\begin{array}{c}\text { Personal } \\
\text { portal (58) }\end{array}$ & $\begin{array}{c}\text { Geography } \\
\text { e-week (51) }\end{array}$ & $\begin{array}{c}\text { Geography } \\
\text { Information (26) }\end{array}$ & $53.86 \%$ \\
\hline 2012 & 244 & $\begin{array}{c}\text { JiZhi photo } \\
\text { Contest (70) }\end{array}$ & $\begin{array}{c}\text { Member } \\
\text { activity (54) }\end{array}$ & $\begin{array}{c}\text { Visit of Chinese } \\
\text { heritage (20) }\end{array}$ & $59.02 \%$ \\
\hline 2013 & 74 & $\begin{array}{c}\text { Member } \\
\text { activity (28) }\end{array}$ & $\begin{array}{c}\text { 2013 Campus } \\
\text { Zhike } \\
\text { Challenge (20) }\end{array}$ & $\begin{array}{c}\text { Foreword } \\
\text { Articles (7) }\end{array}$ & $74.32 \%$ \\
\hline
\end{tabular}

Another kind of links are linked to its own Micro-blog, the data of content analysis as shown in Table 6. The use of micro-blog accounts takes a large proportion and remains relatively stable, this part strengthens the interaction effect, enhance the activity of periodical in forward, reply and remind etc. CNG continued to build the main micro-blog topics, successfully to reflects the changes in main content every year, except the major events such as the 60th anniversary and permanent activities like campus Zhike and photography contest, reflecting the sustainability of topics. In 2009 and 2010, micro-blog is still in its early stage, thus the topic planning is obviously insufficient. In addition, the main content of these two parts relatively stable, around $65 \%$ of the 3 types of micro-blogs, both rich themes and emphasis on core content have been taken into account.

Table 6. The Content Analysis of CNG Links

\begin{tabular}{|c|c|c|c|c|c|c|c|}
\hline \multirow{2}{*}{$\begin{array}{l}\text { Year } \\
2009\end{array}$} & \multirow{2}{*}{$\begin{array}{c}\begin{array}{c}\text { Number } \\
\text { of Three } \\
\text { Types }\end{array} \\
6\end{array}$} & \multicolumn{5}{|c|}{ Top 5 Contents } & \multirow{2}{*}{\begin{tabular}{|c} 
Proportion \\
$100 \%$
\end{tabular}} \\
\hline & & $\begin{array}{l}\text { \#Weibo } \\
\text { accounts\# } \\
(5)\end{array}$ & $\begin{array}{c}\text { \#ideal } \\
\text { job\# (1) }\end{array}$ & & & & \\
\hline 2010 & 286 & $\begin{array}{l}\text { \#Weibo } \\
\text { accounts\# } \\
\quad(158)\end{array}$ & $\begin{array}{l}\text { \#Covers of } \\
\text { CNG\# (98) }\end{array}$ & $\begin{array}{c}\text { \#most } \\
\text { beautiful } \\
\text { clouds in } \\
\text { china\# (7) }\end{array}$ & $\begin{array}{l}\text { \#record china } \\
\text { for } 60 \text { years- } \\
\text { mission of a } \\
\text { magazine\# (4) }\end{array}$ & $\begin{array}{c}\# 60 \text { th } \\
\text { anniversary of } \\
\text { CNG\# (2) }\end{array}$ & $94.06 \%$ \\
\hline 2011 & 741 & $\begin{array}{c}\text { Weibo } \\
\text { accounts } \\
(283) \\
\end{array}$ & $\begin{array}{c}\text { \#Campus } \\
\text { Zhike\# } \\
(74) \\
\end{array}$ & $\begin{array}{l}\text { \#love is } \\
\text { on the } \\
\text { way\# }(60)\end{array}$ & $\begin{array}{c}\text { \#60th } \\
\text { anniversary } \\
\text { of CNG\# (28) }\end{array}$ & $\begin{array}{c}\text { \#salt\# } \\
(26)\end{array}$ & $63.56 \%$ \\
\hline 2012 & 1,769 & $\begin{array}{l}\text { Weibo } \\
\text { accounts } \\
(713)\end{array}$ & $\begin{array}{c}\text { \#portiait } \\
\text { of Inner } \\
\text { Mongolia\# } \\
(171)\end{array}$ & $\begin{array}{c}\text { \#Jeep JiZhi } \\
\text { photo } \\
\text { contest\# } \\
(135) \\
\end{array}$ & $\begin{array}{c}\text { \#potriait of } \\
\text { Zhejiang\# (53) }\end{array}$ & $\begin{array}{c}\text { \#portiait of Inner } \\
\text { Mongolia } \\
\text { have told } \\
\text { me\# (46) }\end{array}$ & $63.2 \%$ \\
\hline 2013 & 1,169 & $\begin{array}{l}\text { Weibo } \\
\text { accounts } \\
(428)\end{array}$ & \begin{tabular}{|c|} 
\#poems, \\
paintings, \\
mountains \\
and rivers\# \\
$(120)$
\end{tabular} & $\begin{array}{l}\text { Campus } \\
\text { Zhike } \\
(82)\end{array}$ & $\begin{array}{l}\text { \#reading } \\
\text { club\# (72) }\end{array}$ & $\begin{array}{c}\# 10 \text { years } \\
\text { 2013Jeep JiZhi } \\
\text { photo } \\
\text { Contest\# (66) }\end{array}$ & $65.7 \%$ \\
\hline
\end{tabular}




\section{Visualization Analysis of its Communication Effect}

The traditional science communication is one-way, mainly by virtue of the mass media, the spread of this form is often monopolized by a few authority (Li, 2014). The audience-constructed role of communication effectiveness is minimal, but in the Micro-blog science communication, the audience can disseminate science to expand the chain of the spread, and strengthen the effect. By forwarding, reviewing, and other indicators of the chain can detect certain communication effect. As shown in Table 7, with the development of time, attention raised by CNG Micro-blog increasing, especially the forwarding number. In 2009 each Micro-blog's average number of comments was 6.85, forwarding number was 11.1, while in 2011 the number of comments rose to 60.38 , the forwarding number climbed to 145.41. From the beginning of 2012, forwarding number growth slowed and showed a downward trend, the number of comments also declined slightly, each Micro-blog's forwarding number and comments were stabilized of 50 times and 150 times on average.

Table 7. Forwarding Number and Comments of CNG on Average

\begin{tabular}{|l|c|c|c|c|c|}
\hline Year & $\mathbf{2 0 0 9}$ & $\mathbf{2 0 1 0}$ & $\mathbf{2 0 1 1}$ & $\mathbf{2 0 1 2}$ & $\mathbf{2 0 1 3}$ \\
\hline Comments & 6.85 & 28.12 & 60.38 & 47.83 & 42.86 \\
\hline $\begin{array}{l}\text { Forwarding } \\
\text { Numbers }\end{array}$ & 11.1 & 60.1 & 145.41 & 145.41 & 150.4 \\
\hline
\end{tabular}

A popular science post on February 8, 2012, for example, involved history of a maritime merchant along the coast of Zhejiang, caused 1,504 forwards and 565 comments, with a picture added and words for extended information. Using the PKUVIS (Ren, Zhang, Wang, Li, \&, Yuan, 2014) to analyze the chain of the communication, the results of this micro-blog are listed in Figure 2 . VIP accounts that forwarding this micro-blog only take $7 \%$, but the small nodes of CNG itself in Figure 2 indicate its low involvement in forwarding, a large number of forwards by VIP users contributed to an effect of second transmission. These active VIP followers such as "Fourth District of Zhoushan islands in China" and "Southeast Branch three_three" etc led to a certain amount of forwards, especially "Xue Manzi" as an important node, reached a new climax of forwarding as high as 336. This micro-blog was forwarded on more than 6 levels, illustrates that substantial popular science micro-blogs not only are easier to achieve continuous deep spread, but also fit the communication ideas of CNG "Content Is King".

\section{Discussion}

As the most mature representative of popular science journals in the micro-blog platform, $\mathrm{CNG}$ has shown stable publishing patterns and mechanism with wide range of audiences and a good basis for dissemination. While compared with similar micro-blogs, the communication effect remains to be improved. Take Science Squirrels for example, the average number of 
forwarded micro-blog posts is much bigger than $\mathrm{CNG}$, though with less than half of the number of fans of CNG. For example, a post about "common knowledge of earthquake" (SongShuHui, 2013) was forward up to 68,355 and its comments also reached 9, 119.

Figure 2. The Visualization Analysis of Weibo "Wohuan", August 8, 2012

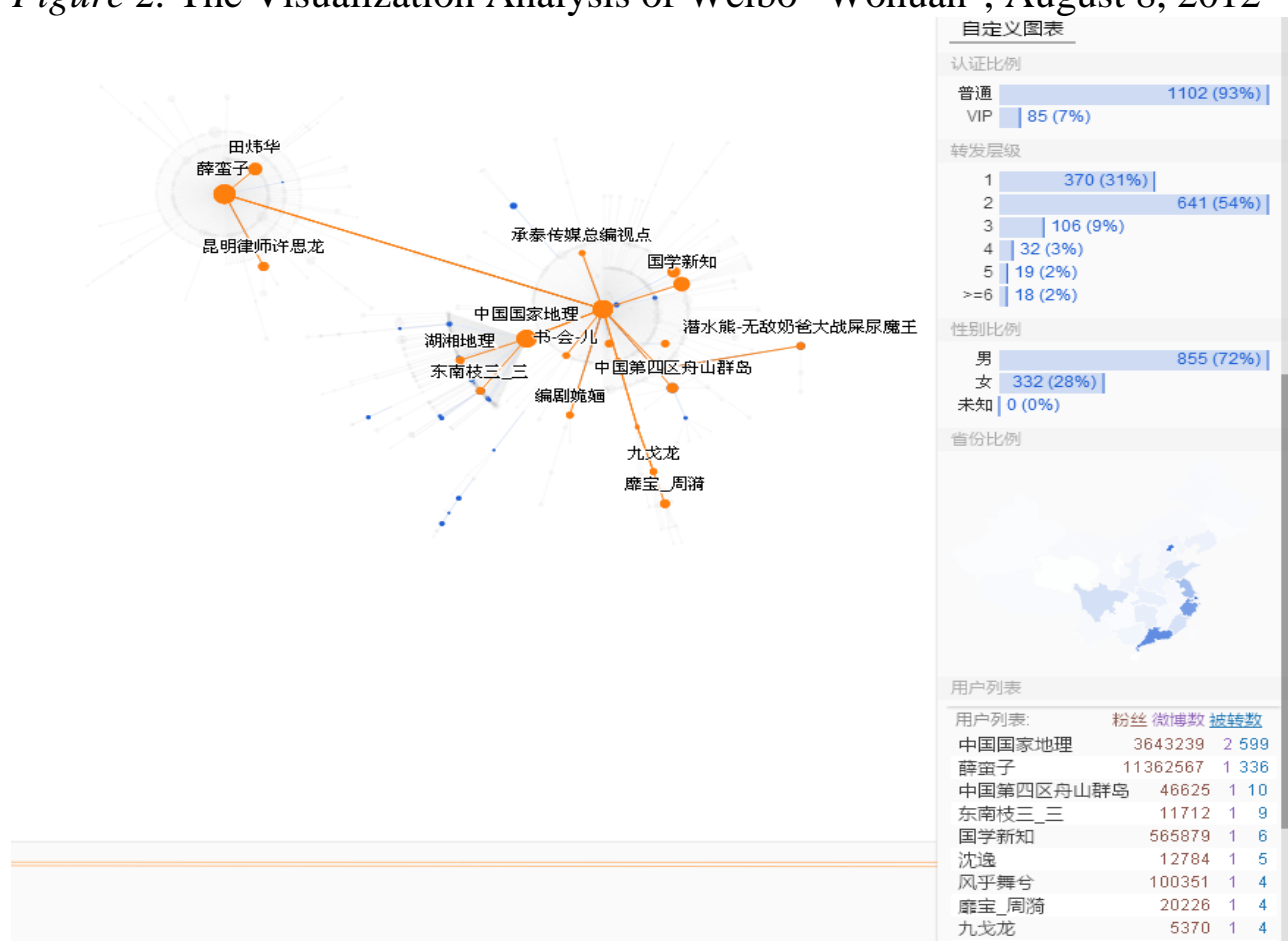

Analyses conducted from the angle of compose showed that, some microblogs were lack of relevant links, complete text description and attractive writing style, those may relate to CNG's relatively high scientific position, while more approachable words and interactions undoubtedly make the microblog get more attention (Chen, \& Hao, 2014).Therefore in micro-blog writing, we should combine characteristics of network communication and integrate network language style to enhance the accessibility and achieve popularity. Meanwhile, the dominant social media content will transform into visual experience (Qiu et al., 2013), thus it is necessary to integrate all kinds of resources, such as text, pictures, video, and links to achieve multi-dimensional spread. Finally, the interactions with the well-known VIP followers should be enhanced, to realize low cost and nice marketing (Jiang, 2015), to expand communication radius, deepen transmission chain and enhance the effect of science popularization. 


\section{Acknowledgments}

We want to express our thanks to Xueying Wang at the WISE-Lab of Dalian University of Technology for her input for the earlier draft of this paper, and thank her for allowing us to modify the templates that she had developed.

\section{References}

Chang, R., Li, X., Chen, W. (2012). An empirical analysis on the current situation of micro-blog's operation. Media, Aug.: 56-58.

Chen, X., \& Hao, S. (2014). Analysis on discourse communication characteristics of Aerospace Engineering popular science micro-blog. Journal of News Research, May: 45-46.

Jiang, J. (2015). Accelerate the integration of traditional publishing and emerging Publishing Development. Chinese Editorials, Jan.: 4-7.

Li, T. (2014). Dilemma analysis on the development of popular science micro-blogs under the guidance of STS. Social Sciences Review, Oct.: 129-133.

Qiu, C., Huang, Q., \& Lin, S. (2013). Status and reflections of micro-blogs of popular health science journals: analysis based on nigh kinds of journals at sina. Acta Editologica, Jun.: 584-587.

Ren, D., Zhang, X., Wang, Z., Li, J., \& Yuan, X. (2014). WeiboEvents: A Crowd Sourcing Weibo Visual Analytic System. IEEE Pacific Visualization Symposium Notes, 330-334.

SongShuHui (2013). Association of Science Communicators. Retrieved from http://goo.gl/S6YF2L. [Accessed: 23 April 2013]

Zhang, G. (2012). Contents Analysis and application research of popular science journals' micro-blog: take Sina Weibo for example. Science Technology and Publication, Jun.: 106-109.

Zhao, Q. (2014). Analysis of microblogs on the Science education journals (Unpublished dissertation thesis). Beijing Institute of Graphic Communication, China. 